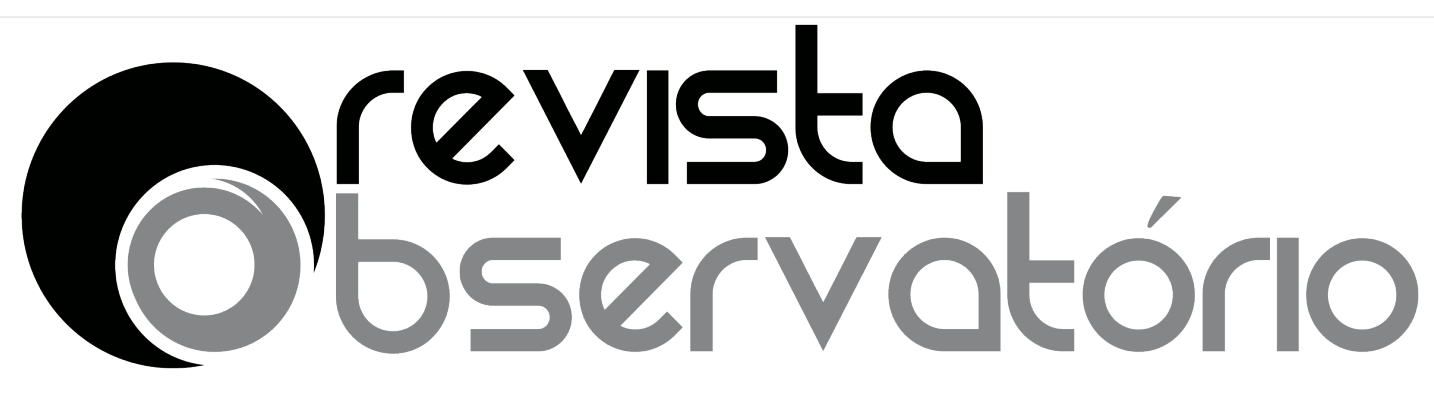

ISSN n² 2447-4266

Vol. 4, n. 2, Abril-Junho. 2018

DOI: http://dx.doi.org/10.20873/uft.2447-4266.2018v4n2p28

\title{
A NATURALIZAÇÃO DA CULTURA DA VIOLÊNCIA E A CRÍTICA DA RAZÃO
}

Abrindo o segundo número de 2018 da Revista Observatório temos a produção artística de Adriano Alves da Silva que produziu uma reflexão visual sobre a violencia nas mídias. Nossa capa já abre o debate! Muito trabalho foi realizado nesse percurso para ajustar a revista aos indexadores internacionais. Como leitor, você não o viu nas páginas que leu, mas ele está presente no campo dos metadados dos artigos dentro do sistema OJS, nas referências e no campo bibliométrico dos artigos. Ocorreu também nesse período a migração de todos os artigos (disponibilizados em outras linguagens) para dentro do sistema da revista, melhorando a agilidade de resposta de quem os utiliza. Todos os voluntarios trabalharam duro para termos um periódico de qualidade!

Nesse número publicamos dois dossiês temáticos: o primeiro intitulado $\mathbf{A}$ NATURALIZAÇÃO DA CULTURA DA VIOLÊNCIA NA SOCIEDADE MIDIATIZADA organizado pelo profesor Geraldo da Silva Gomes da Universidade Estadual do Tocantins e do Centro de Estudos e Aperfeiçoamento Funcional (Cesaf/MPTO), que destaca o fenômeno da violência em interface com a comunicação; o segundo, intitulado EDUCAÇÃO, CULTURA E CRÍTICA DA RAZÃO: PERSPECTIVAS CONTEMPORÂNEAS, organizado pelos professores Adriano Machado Oliveira e Juciley Silva Evangelista Freire ambos da Universidade Federal do Tocantins (UFT), discutem a problemática da Educação e sua inter-relação com a Cultura e os desafios postos pela contemporaneidade para as novas e velhas formas do 


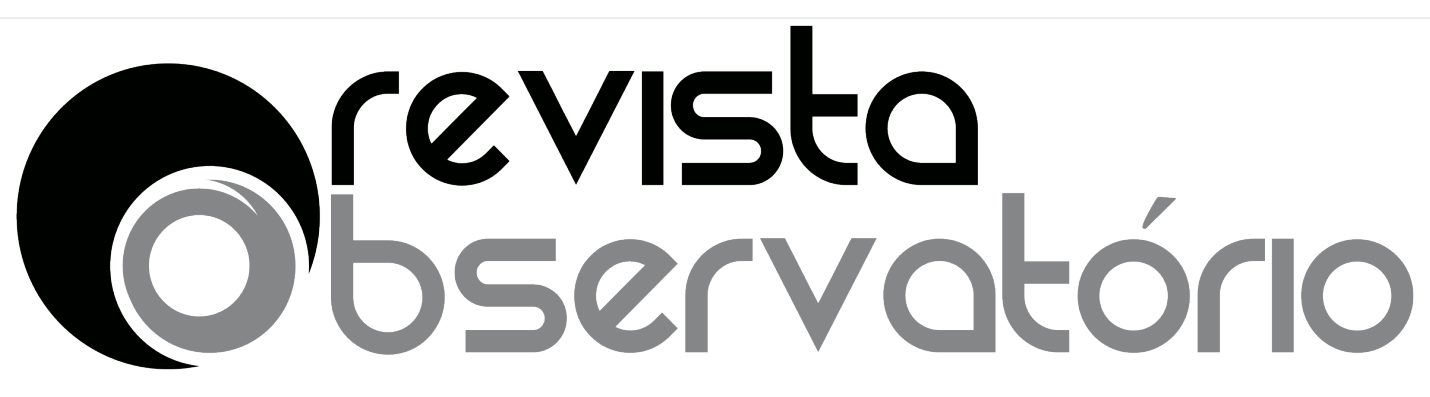

ISSN n² 2447-4266

Vol. 4, n. 2, Abril-Junho. 2018

DOI: http://dx.doi.org/10.20873/uft.2447-4266.2018v4n2p28

pensamento ou das racionalidades operantes na construção da realidade social.

De início foi pensado para o presente Dossiê Temático I uma trilha de textos que abordassem estudos sobre a naturalização da cultura da violência na sociedade midiatizada. No meio do caminho, as falas, as experiências, os pontos de vista, intencionalidades, angulações teóricas e metodológicas e os respectivos lugares de atuação das interlocutoras e interlocutores convidados interpuseram-se abrindo, caleidospicamente, a proposta inicial.

O dossiê temático espalhou-se como uma grande rede de ideias, convites à reflexão, semeaduras de ensinamentos, compartilhamento de saberes e preocupações das autoras e autores com as pessoas que estão no Planeta vivendo sob multifacetadas características do fenômeno da violência em interface com a comunicação.

É verdadeiramente salutar, no prisma da análise cognitiva, perceber que pessoas que labutam em distintas áreas ou na área comunicacional estão preocupadas com os acontecimentos múltiplos que constróem a realidade, refletem sobre isso, compartilham seus saberes e buscam táticas para que o conhecimento seja difundido intra e extra muros das universidades. Ao olhar para tras, duas décadas pelo menos, via-se muita gente pelejando para firmar muros em suas áreas de pertencimento; hoje, os respiros começam a surgir ou seja, a necessidade do estabelecimento de partilha de conhecimento alimenta utopias e eutopias frente ao distópico horizonte da violência naturalizado pela mídia. A necessidade de comunicar para além dos muros é muito importante.

Assim, o dossiê temático teve pouca preocupação em trabalhar com grande quantidade de textos. No veio pedagógico, optou-se por textos que se encadeiam, enfeixam temas, possibilitam alinhamentos analíticos contrastivos ou associativos. Mantevese a apresentação dos textos seguindo ordem alfabética dos nomes das autoras e autores, contudo o convite para quem se deixar seduzir pela proposta é a leitura livre de cada um dos materiais. Construa sua trilha de entendimento sobre as preocupações com a relação comunicação-mídia e violência apresentadas. 


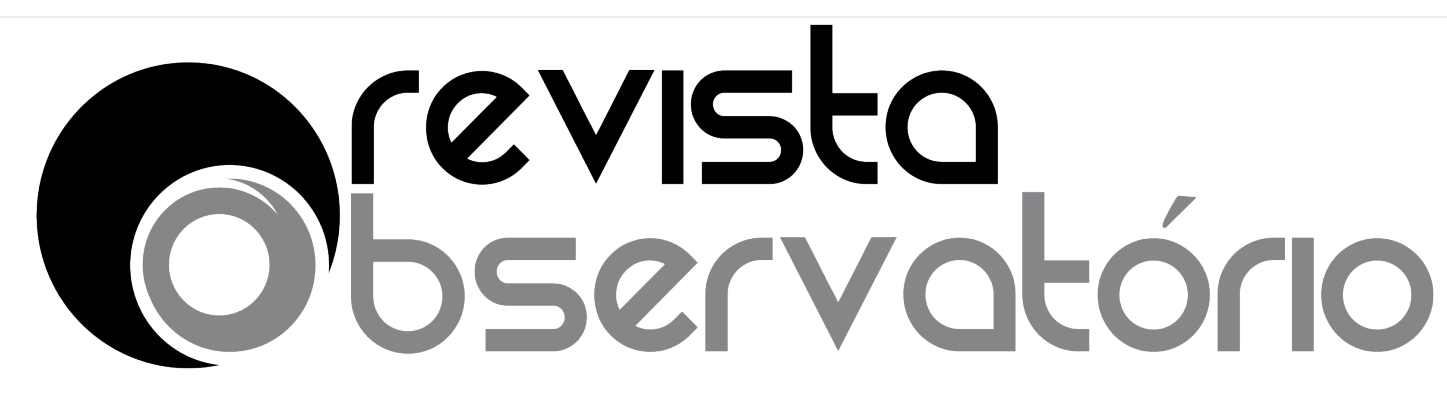

ISSN n² 2447-4266

Vol. 4, n. 2, Abril-Junho. 2018

DOI: http://dx.doi.org/10.20873/uft.2447-4266.2018v4n2p28

Adrían Tarín e Meysis Carmenati González em SOLO LOS HOMBRES SON POLÍCIAS: ORDEN PÚBLICO VIOLENCIAS HETERONORMADAS Y SUS REFLEJOS EN THE WIRE realizam um estudo sobre as construções simbólicas que são perpassadas numa série televisiva, gênero em expansivas ofertas e consumos na última década, e como isso nos afeta. Belén Zurbano Berenguer em COMUNICACIÓN, PERIODISMO Y VIOLÊNCIAS CONTRA LAS MUJERES EN ESPAÑA: Reflexiones en torno a un estado de la cuestión situa a importância de se ater ao estudo do jornalismo. Uma nova safra de pesquisadoras e pesquisadores despontam ao trazer com seriedade e comprometimento as questões de gênero frente a violência midiatizada. Os artigos trabalhados são convidativos para estudantes da graduação e pós-graduação, provocam elucidando.

Suely Aldir Messeder e Clebemilton Gomes do Nascimento em CINE BLASFÊMIA: uma narrativa de censura, enfrentamentos e (re)existências trazem à baila a importância de se discutir a blasfêmia como estratégia política de resistência aos regimes regulatórios de gênero e sexualidade. Pensar e trabalhar com a perspectiva da blasfêmia em tempos de opiniões coléricas, separatistas e intolerantes, sempre é algo proibido, visto como pecaminoso. Mas o que seria da vida sem o riso crítico e irônico que uma blasfêmia não provoca. O texto cativa ao criar a vontade que na esquina de sua casa tenha um Cine Blasfêmia para exibir e discutir filmes com " A excêntrica família de Antônia".

Rute Saraiva, da Universidade de Lisboa, nos aporta com um estudo sobre A REGULAÇÃO DA VIOLÊNCIA MEDIÁTICA EM PORTUGAL. Ainda ambos os países se encontram distantes no saber como cada um trabalha a regulação da violência midiática. Não adaptamos o texto ao acordo ortográfico vigente da língua portuguesa, mantivemos os material em sua integralidade, os lusitanos não o observam. Mantivemos assim também para se ter o gostinho de pensar a escutar a pronúncia fechada e rápida de Rute Saraiva, que apresenta no viés jurídico português soluções de hetero-, co e autorregulação que admitem abordagem precaucionaria na proibição de programas agressivos. 


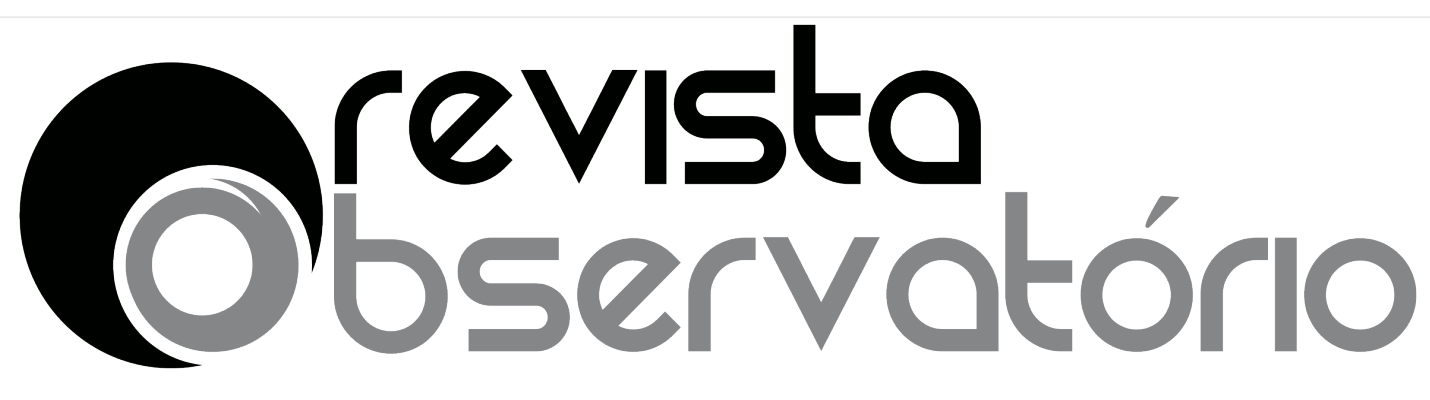

ISSN n² 2447-4266

Vol. 4, n. 2, Abril-Junho. 2018

DOI: http://dx.doi.org/10.20873/uft.2447-4266.2018v4n2p28

Analía Soria Batista e Wellinton Caixeta Maciel nos colocam a séria reflexão sobre a PRISÃO COMO GUETO: a dinâmica de controle e de extermínio de jovens negros pobres. Em senda temática aproximada, Geraldo da Silva Gomes, aporta com ELEMENTOS PARA ENTENDIMENTO DOS PROCESSOS COMUNICACIONAIS: OS ESPAÇOS DOS REGIMES PRISIONAIS SEMIABERTO E FECHADO EM PALMAS-TO. Ambas as temáticas trazem outras realidades para a reflexão, a de vida de pessoas que se encontram do outro lado da tela ou monitor de TV e por detrás das grades. Ao se mencionar a cidade de Palmas, trouxemos a análise de Giuliano Orsi Marques de Carvalho, Olivia de Campos Maia Pereira e Marcos Antônio dos Santos para refletirem sobre o que esse espaço comunica: PALMAS EM TRÊS ATOS: projeto urbanístico, implantação e consolidação da capital do Tocantins.

Maria Elisa Gonzalez Manso, Renato Gonzalez Raposo e Ruth Gelehrter nos alertam sobre ao MÍDIAS DIGITAIS E AS INVISÍVEIS VIOLÊNCIAS CONTRA IDOSOS. O texto aponta que determinadas categorias de violência encontram-se tão naturalizadas que sequer são abordadas pelos veículos midiáticos, tecnologias reprodutoras do discurso que estereotipa a velhice. Beltrina Côrte e Bruna Suelem Mendes dos Santos discutem a prática da contenção junto aos idosos, no texto EM NOME DO CUIDADO SE NATURALIZA A VIOLÊNCIA: o caso da contenção, isto é, como mecanismos discursivos e práticos são colocados em ação engendrando mais e mais situações de exclusão e degradação dos idosos.

A cultura da violência espelhada-espalhada pela sociedade midiatizada a cada a dia tende a se ampliar. De nossos lugares de falas e práticas necessitamos analisar esse processo e propor soluções para sua superação. Almeja-se que os textos que compõem o presente dossiê sejam acessados, lidos, compartilhados, que gerem reflexão e a curiosidade do aprender para engajar-se em busca de propostas de resistências. Agradecemos às autoras e autores pela contribuição. 


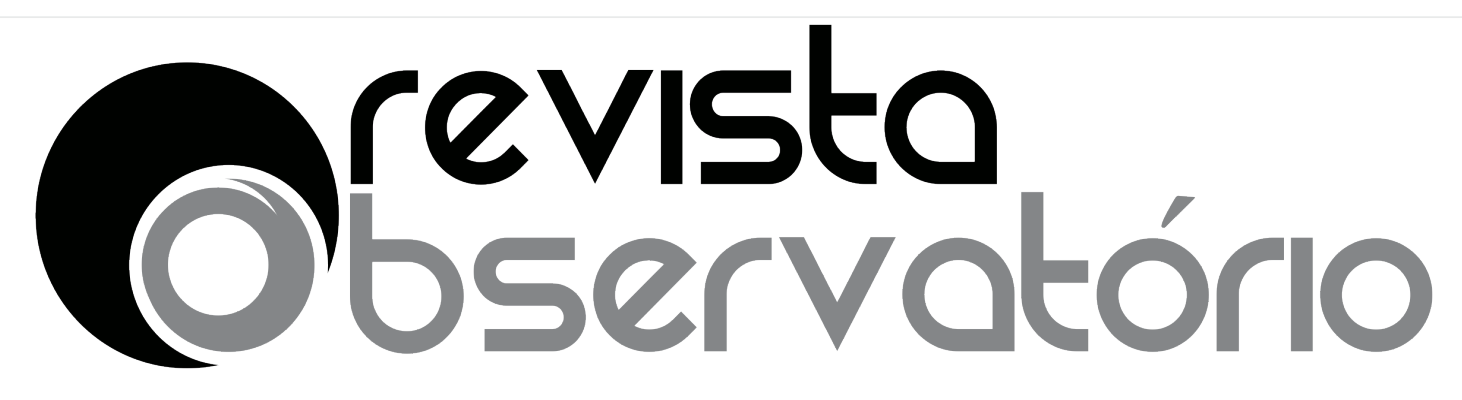

ISSN n² 2447-4266

Vol. 4, n. 2, Abril-Junho. 2018

DOI: http://dx.doi.org/10.20873/uft.2447-4266.2018v4n2p28

No segundo dossiê, EDUCAÇÃO, CULTURA E CRÍTICA DA RAZÃO: Perspectivas contemporâneas, organizado por ADRIANO MACHADO OLIVEIRA e JUCILEY SILVA EVANGELISTA FREIRE, são reunidos textos de pesquisadores de diversas abordagens teórico-metodológicas para a análise da problemática da Educação e sua inter-relação com a Cultura e os desafios postos pela contemporaneidade para as novas e velhas formas do pensamento ou das racionalidades operantes na construção da realidade social. Os textos reunidos, além da abrangência nas abordagens teóricas, possuem também abrangência institucional, pois seus autores são professores-pesquisadores de diversas universidades e de áreas do conhecimento também variadas, tais como da filosofia, da história, da pedagogia e da psicologia. Feitas essas considerações, cumpre-nos assinalar algumas questões que, acreditamos, compõem um pano de fundo sociocultural comum a todos os estudos e ensaios que ora apresentamos.

Trata-se da multiplicidade de discursos que caracterizam a contemporaneidade. Longe dos consensos relativamente duradouros, do que Zygmunt Bauman caracterizou em seus escritos como modernidade sólida, o que temos na atualidade é uma pulverização de narrativas, nada convergentes - e, embora paralelas, nem sempre dispostas ao diálogo. São discursos nos mais variados campos das humanidades, os quais, quase sempre, advogam para si um certo quinhão de verdade teórica, ideológica, científica. Verdades estas muitas vezes sustentadas como provisórias, mas nem por isso sempre capazes de fomentar um diálogo que pudesse erguer consensos temporários.

Vive-se, na atualidade, por conseguinte, a pluralidade de verdades teóricas, a dispersão de perspectivas conceituais no campo das humanidades. O que, a nosso ver, fortalece cada vez mais os postulados de Thomas Kuhn, ao defender a temporalidade do que se apresenta como verdade científica e sua indissociável relação com os acordos historicamente datados entre pesquisadores. 


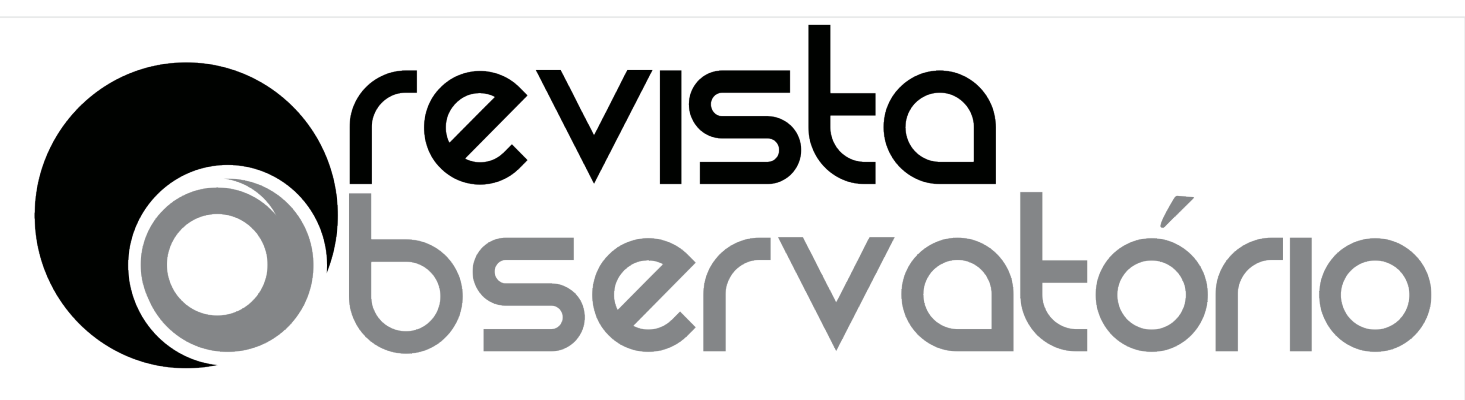

ISSN n² 2447-4266

Vol. 4, n. 2, Abril-Junho. 2018

DOI: http://dx.doi.org/10.20873/uft.2447-4266.2018v4n2p28

Em nosso país, por sua vez, tal cenário ainda se vê incrementado pelas preocupações dos pesquisadores em agregarem quantidades e mais quantidades de artigos publicados em seus espetaculares currículos lattes. Como vem assinalando criticamente Roberto Biachetti, destacado teórico no campo da educação e professor da Universidade Federal de Santa Catarina, vivemos em nossos currículos profissionais a exacerbação de uma cultura do narcisismo e do espetáculo. Tudo se passa, pois, como se o vértice da vida do pesquisador fosse acumular publicações, e logo computa-las digitalmente, para uma suposta e imediata visibilidade para seus pares. Progressivamente, nessa direção, perde-se a profundidade teórica dos trabalhos, o acabamento conceitual e argumentativo, em favor de uma replicação de discursos já postos em outros escritos e uma fragmentação da apresentação de resultados de estudos empíricos - tudo com vistas a maximizar as possibilidades de que um mesmo estudo ou pesquisa possa resultar em diversas modalidades de publicações.

Trata-se, assim, de uma espetacularização da profissão docente no ensino superior. Conceito este aqui tomado a partir de Guy Debord (1997a, 1997b, 1995, 1961), o que vem a significar que estamos a construir realidades fantasmáticas, as quais existem somente em nossas mentes, em não raros momentos, acerca da importância e alcance do que fazemos. Em detrimento, cabe ressaltar, de um amadurecimento maior de pressupostos e convicções teóricas.

A pulverização discursiva, desse modo, encontra-se encadeada com predisposições no terreno anímico, onde no âmago do sujeito pesquisador parece encontrar-se já o desejo de visibilidade, de ostentação de supostos predicados intelectuais. A diversidade teórica, a qual num primeiro momento pode parecer representar efetivamente um enriquecimento de arcabouços conceituais, logo, em não poucos casos, mostra ser um amontoado de precipitações empíricas e discursivas (FROMM, 1976, 1988).

O presente dossiê temático II, por tudo isso, longe de ter a pretensão de apresentarse como propositor de reflexões absolutamente novas, tem o intuito de fornecer indícios 


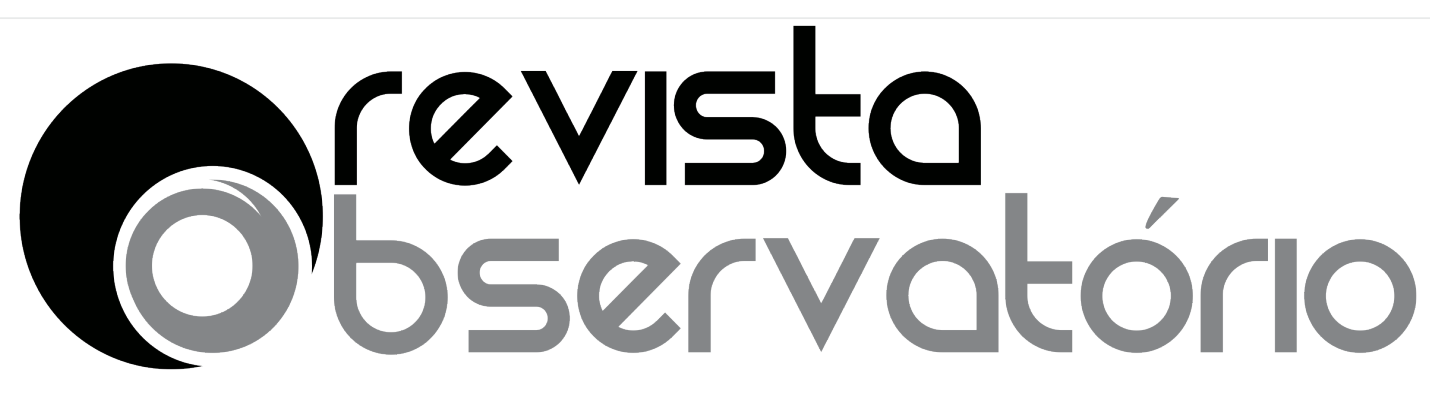

ISSN n² 2447-4266

Vol. 4, n. 2, Abril-Junho. 2018

DOI: http://dx.doi.org/10.20873/uft.2447-4266.2018v4n2p28

para que possamos pensar criticamente a contemporaneidade em distintos domínios das humanidades. Territórios estes nos quais movimentam-se sujeitos que, tal como nós, tem buscado tatear os contornos do cenário em que vivemos, em busca de estratégias de vida que possam se mostrar eficazes para lidar com a instantaneidade e fluidez das narrativas sociais.

$\mathrm{Na}$ ausência, outrossim, de verdades teóricas e empíricas definitivas, na falta de consensos, optamos pela tentativa de olhar para o sujeito a partir de distintos aportes teóricos e metodológicos, sem qualquer pretensão narcisista de que essa compilação de trabalhos venha a constituir sinal de conquistas intelectuais ou acadêmicas - senão e somente um esforço modesto de indicar olhares em construção, argumentos em estágio embrionário, convicções erguidas em meio à incerteza. Uma singela contribuição, desse modo, às tentativas atuais de compreender a formação do sujeito e a educação frente às narrativas hegemônicas da atualidade - dentre elas, o imperativo da visibilidade e suas nefastas consequências.

Nessa perspectiva, iniciamos o Dossiê $\|$ com o artigo MODERNIDADE, CIÊNCIA, FILOSOFIA, de José Ternes, que faz incursões por alguns textos de historiadores do pensamento ocidental objetivando apreender aspectos decisivos da modernidade, como também mostrar que no tempo presente ocorre o desencantamento das promessas, demasiadamente otimistas, dos séculos XVII e XVIII. Do ponto de vista epistemológico, o autor demonstra que a revolução da modernidade tem a ver com mudanças de objetos, argumentando que entender nossa época significa perguntar-se acerca da natureza dos novos objetos nascidos ou constituídos a partir dos começos do século XIX.

No artigo A REINVENÇÃO DA VIDA MODERNA NA TRANSIÇÃO DO SÉCULO XIX PARA O SÉCULO XX: de uma cultura de fundamentos ao relativismo contemporâneo, de Rogério Ferrer Koff, problematiza-se a noção moderna de humanidade, enquanto gênero universal, baseada em uma certa visão da natureza humana, em uma cultura de 


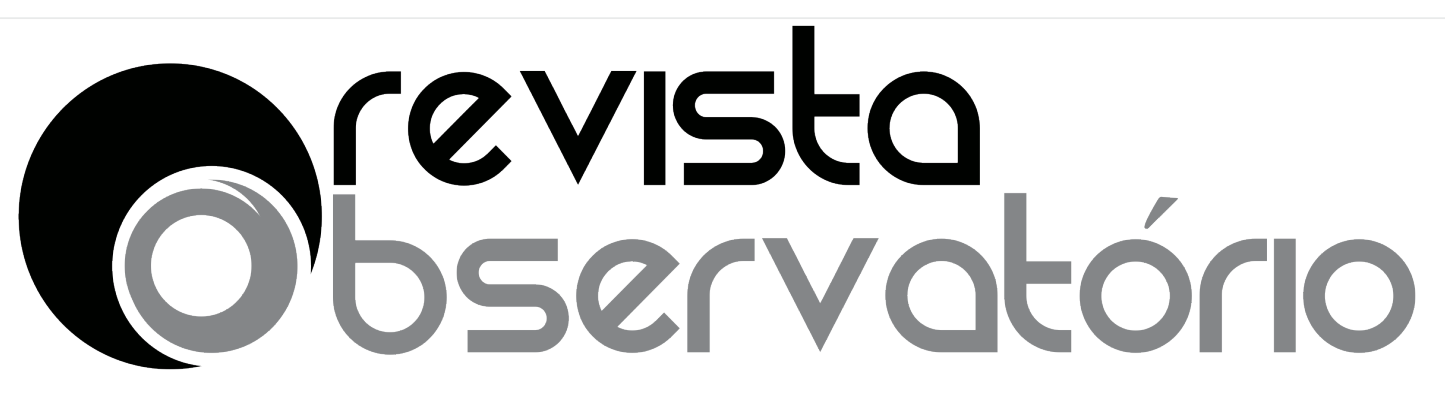

ISSN n² 2447-4266

Vol. 4, n. 2, Abril-Junho. 2018

DOI: http://dx.doi.org/10.20873/uft.2447-4266.2018v4n2p28

fundamentos e em uma profunda convicção na existência de uma essência universal do homem. A crise da noção de essência faz surgir a historicidade como a forma cabal do pensamento no século XIX, o que teria quebrado o caráter unívoco da palavra "ciência". Para o autor, o pensamento do Século XX e do alvorecer do novo milênio são herdeiros desta crise, que substituiu as verdades absolutas pelas categorias de heterogeneidade, diferença e relativismo.

O artigo A RECONCILIAÇÃO FORMAL ENTRE TEORIA E PRÁTICA: uma problematização da concepção pragmática, de José Oto Konzen, apresenta uma crítica à estrutura lógica do empreendimento pragmático ao problematizá-lo histórica e filosoficamente. Konzen parte da constatação de que ao longo das últimas décadas, na cultura contemporânea de um modo geral e na cultura educacional de modo particular, vem se afirmando um crescente desprestígio em relação à teoria e um apelo à valorização da prática, bem caracterizado pelo uso de expressões do tipo "para que serve a teoria?", "na prática, a teoria é outra!" e "mais vale a prática que a gramática!". A análise é desenvolvida a partir do diálogo com dois autores da tradição pragmática e neopragmática americana: o projeto filosófico-educativo de John Dewey, e de maneira complementar, com Richard Rorty.

No artigo A CONSTITUIÇÃO DO SER SOCIAL: TRABALHO E FORMAÇÃO HUMANA EM MARX, Juciley Silva Evangelista Freire, busca apreender os fundamentos da crítica de Marx aos postulados liberais da relação indivíduo e sociedade, evidenciando seus desdobramentos para a constituição do ser social e histórico e suas influências para a concepção de formação humana numa perspectiva emancipadora. Para alcançar esse objetivo, a autora recorre aos debates travados por Marx com os economistas políticos e às suas controvérsias filosóficas com Feuerbach e Hegel, expressos nos Manuscritos de $1844 \mathrm{e}$ nas Teses sobre Feuerbach, aos textos $A$ Ideologia Alemã, escrito conjuntamente com Engels, e Contribuição à crítica da economia política. 


\title{
Crevisto
}

ISSN n² 2447-4266

Vol. 4, n. 2, Abril-Junho. 2018

DOI: http://dx.doi.org/10.20873/uft.2447-4266.2018v4n2p28

\begin{abstract}
Em A AGONIA DO ESPÍRITO EMANCIPADOR DA EDUCAÇÃO PERANTE A INTEGRAÇÃO ESPETACULAR DA SOCIEDADE DE CONSUMO NA FORMAÇÃO ALIENADA DA CONSCIÊNCIA ESTUDANTIL, Renato Nunes Bittencourt aborda aspectos próprios da mercantilização do ensino como produto para os consumidores de diplomas, a partir da constatação de que a Educação, longe de ser um palco neutro da estrutura social, é um dispositivo repleto de discursos ideológicos que falseiam as relações de produção. Argumenta que, a despeito do projeto iluminista de considerar a Educação como uma atividade emancipadora do indivíduo, pode-se constatar que na sociedade capitalista a conversão do sistema educacional aos seus paradigmas alienantes gera uma mitificação do ofício pedagógico como se este fosse uma prática desinteressada, quando em verdade estabelece intricadas relações de poder.
\end{abstract}

No artigo CIÊNCIA E ENSINO: CONTRIBUIÇÕES DA INICIAÇÃO CIENTÍFICA NA EDUCAÇÃO SUPERIOR, Maria José de Pinho, analisa a política da iniciação científica no ensino de graduação como espaço de formação, buscando compreender a política da iniciação científica no ensino de graduação da Universidade Federal do Tocantins a partir de um breve resgate da educação superior no Brasil e sua ênfase na pesquisa, bem como faz uma incursão na história da iniciação científica no Brasil e na UFT, a partir do entendimento da pesquisa como espaço de formação.

No artigo ADOLESCÊNCIA, CULTURA E SOCIEDADE DO ESPETÁCULO, Adriano Machado Oliveira e Márcia Machado buscam fornecer elementos teóricos para pensar o sujeito contemporâneo e, em particular, aqueles que atravessam a adolescência, que encontram-se imersos significativamente em uma sociedade tecida pela imagem. Nesse contexto, argumentam que os anúncios publicitários televisivos trabalham efetivamente, porém, de modo implícito, com as categorias de sucesso e fracasso social, bem como com as categorias de felicidade e infelicidade. Os autores argumentam que 0 anúncio publicitário não somente apresenta a mercadoria enquanto tal (propriedades, preço, 


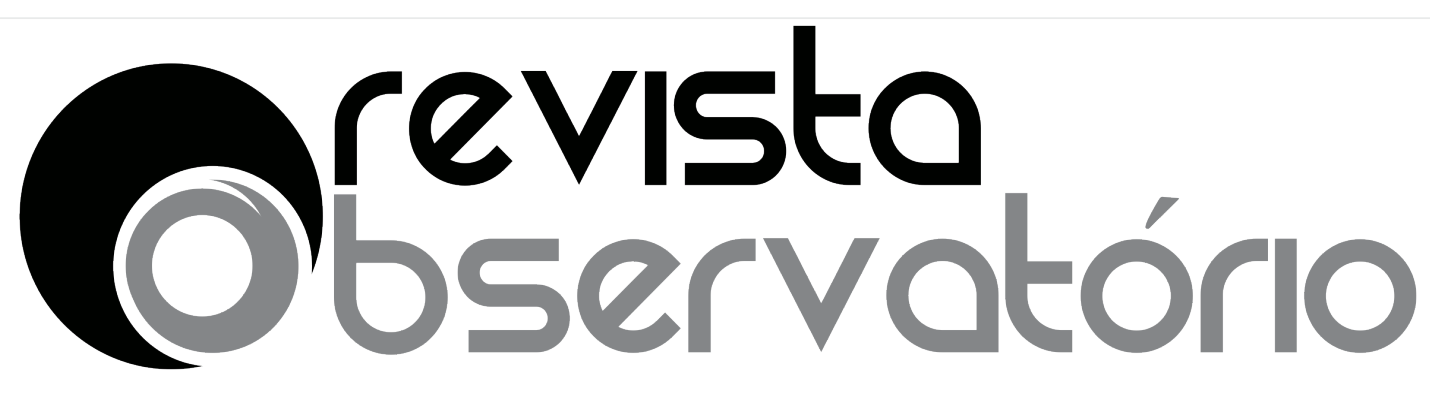

ISSN n² 2447-4266

Vol. 4, n. 2, Abril-Junho. 2018

DOI: http://dx.doi.org/10.20873/uft.2447-4266.2018v4n2p28

utilidades), mas igualmente a associa a elementos puramente subjetivos (apreço social, provimento de bem-estar familiar, sucesso profissional, afirmação de identidades de gênero, filiação a estilos de vida e/ou ideologias). $O$ artigo conclui que nesse contexto saturado de imagens, o outro próximo perde sua caução (FREIRE-COSTA, 2005), e dele os adolescentes já não necessitam para a construção de si e da própria noção de alteridade.

No artigo RELEYENDO ADOLESCENCIA, POSMODERNIDAD Y ESCUELA: veinte años después, Silvia Di Segni retoma um estudo publicado em 1993, com Guillermo Obiols sobre Adolescência, pós-modernidade e escola, analisando agora a chamada crise da modernidade/pós-modernidade, a adolescência e o ensino médio permeados por ela. A questão norteadora desta releitura é: o que mudou em vinte anos? A autora adverte que devido a ausência de Guillermo Obiols, para atualizar o período de análise e postos-chaves em relação à escola e adolescência o texto será uma releitura parcial desse trabalho anterior. São incorporados à análise os conceitos de sociedade disciplinar e sociedade de controle (Deleuze, 1991) para enfatizar que nos tempos atuais não existem mais algumas certezas.

No artigo QUE AUSCHWITZ NÃO SE REPITA: a educação contra a frieza na primeira infância, de Tatiana Koschelny Pereira, parte-se da consideração de que a história da humanidade carrega a marca da violência e de que o debate educacional carece de significado perante a violência. Fundamenta-se nas considerações de alguns autores da Teoria Crítica a fim de buscar a compreensão da exigência de meta educacional: que Auschwitz não se repita, proposta pelo pensador Theodor Adorno, que discute o percurso histórico da civilização em seu movimento contraditório de continuidade e ruptura, apontando que o progresso foi objetivamente tomado como parte de um processo social regressivo. Assim, defende que o trabalho de investigação da experiência formativa na primeira infância desponta como possibilidade de resistência ante a dominação. Conclui, com base no referencial teórico adotado, que por meio da educação e do esclarecimento 


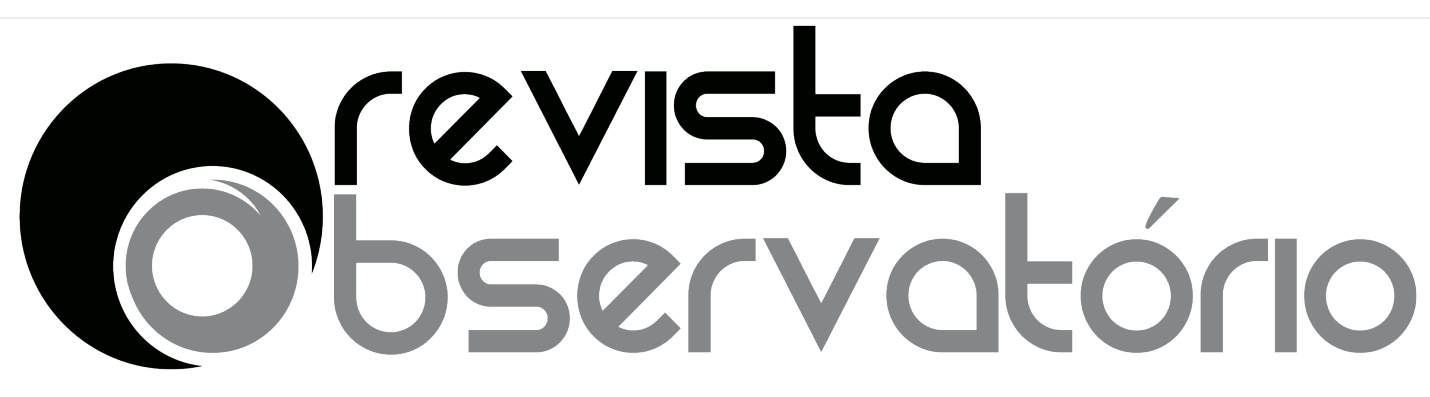

ISSN n² 2447-4266

Vol. 4, n. 2, Abril-Junho. 2018

DOI: http://dx.doi.org/10.20873/uft.2447-4266.2018v4n2p28

numa perspectiva crítica produzir-se-ia uma educação contra a frieza, que carregue em si os germes de um projeto de emancipação humana.

No artigo O EFEITO SUJEITO-DISCENTE E SUJEITO-DOCENTE NO DISCURSO DO DADEB: breve análise discursiva na perspectiva da sustentabilidade, as autoras Janete $\mathrm{S}$. Santos, Sheila C. P. Gonçalves e Karyleilla S. Andrade, fazem fazem uma breve reflexão sobre a (re)construção discursiva do sujeito estudante do ensino médio no documento que versa sobre o Direito à aprendizagem e ao desenvolvimento na educação básica (DADEB), discutindo também a reconfiguração do efeito professor que perpassa o discurso de ressignificação do perfil do sujeito-discente dessa etapa educacional. Problematizam alguns aspectos de discursos de sustentabilidade que se implicam na exequibilidade da nova proposta para a formação do público do ensino médio. A investigação é documental, de caráter interpretativista, e apoia-se em teorias do discurso, como a AD francesa e em reflexões sociológicas, filosóficas e educacionais, a fim de dar conta dos questionamentos iniciais que as novas perspectivas para a educação básica passam a instigar no meio acadêmico. Para tal discussão, o texto trata de: (i) A nova identidade discente ressignificando identidades docentes, (ii) Discursos de sustentabilidade: como naturalizar soluções pouco exequíveis, (iii) Sobre a sustentabilidade do discurso construído pelo DADEB.

Abrindo a seção TEMAS LIVRES, temos o artigo GESTÃO DA COMUNICAÇÃO EM DESASTRES AMBIENTAIS: conflitos de interesse, de práticas e de discursos, de Wilson da Costa Bueno que analisa o caso emblemático da gestão da comunicação associada ao rompimento da barragem do Fundão, em Mariana, no Brasil, com atenção especial às ações e discursos da empresa (Samarco) e a reação da imprensa, das organizações e da opinião pública de maneira geral.

No artigo "APRENDER A LER 'PRA' ENSINAR MEUS CAMARADAS": Reflexões sobre literacia e educação na pós-modernidade, Marcos Cajaíba Mendonça procura desenvolver a 


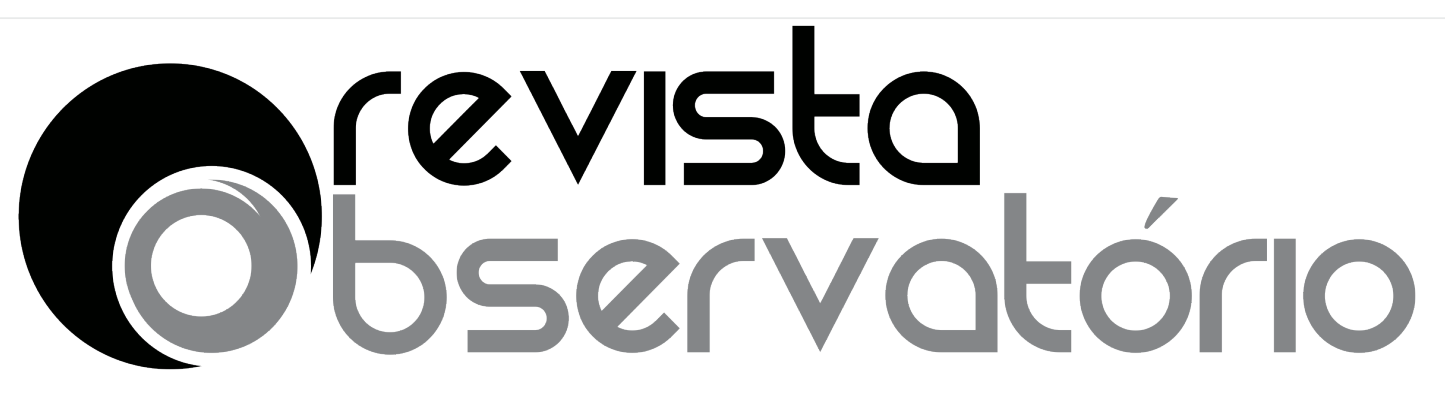

ISSN n² 2447-4266

Vol. 4, n. 2, Abril-Junho. 2018

DOI: http://dx.doi.org/10.20873/uft.2447-4266.2018v4n2p28

relflexão acerca da literacia na pós-modernidade a partir da experiência da educação a distância no Instituto Federal Baiano. Apresenta elementos epistemológicos que pretendem investigar os aspectos da literacia no processo de criação, elaboração e execução do curso Técnico em Secretaria Escolar do Programa PROFUNCIONÁRIO, bem como a análise das propostas de estratégias de utilização dos media pelos professores formadores e equipe pedagógica.

Em RÁDIOS COMUNITÁRIAS NO SUL DO MARANHÃO - CONTEXTOS E LIMITAÇÕES DO TRABALHO RADIOJORNALÍSTICO, Graziela Soares Bianchi e Nayane Rodrigues de Brito propõem a realizar uma análise descritiva dos programas "Jornal da Manhã", da Rádio Buriti FM e "Direitos Humanos: um desafio para a vida", transmitidos pela Arca FM, informativos produzidos por emissoras localizadas no Sul do Maranhão.

Já no artigo ENTRE SUJEITO E PERSONAGEM: a morte de Roberto Bolaños e a vida de Chespirito, Vanessa Matos Santos e Victor Pereira Albergaria realizam um estudo de caso entre as coberturas da morte do ator mexicano Roberto Gómez Bolaños, o "Chespirito", feitas pelo canal FOROtv, pertencente ao conglomerado de mídias mexicano Televisa, e pelo Sistema Brasileiro de Televisão. $O$ aspecto cultural merece especial destaque e, por meio da problematização das distinções existentes entre a morte (substantivo) e o morrer (verbo), o presente estudo demonstra que as coberturas da mídia nestes casos se fazem a partir da relevância da personagem para a identidade do público

Em DO CONTEÚDO À NARRATIVA: um estudo da Pública - Agência de Reportagem e Jornalismo Investigativo, Felipe Simão Pontes e Gabriele Rumor Koster estudam a Agência Pública e os mecanismos de investigação jornalística evidenciadas nos textos das reportagens, como local, autoria e fontes - indícios do investigativo como estratégia narrativa das reportagens da Agência -, bem como a indicação de ferramentas multimidiáticas que auxiliam na composição narrativa. 


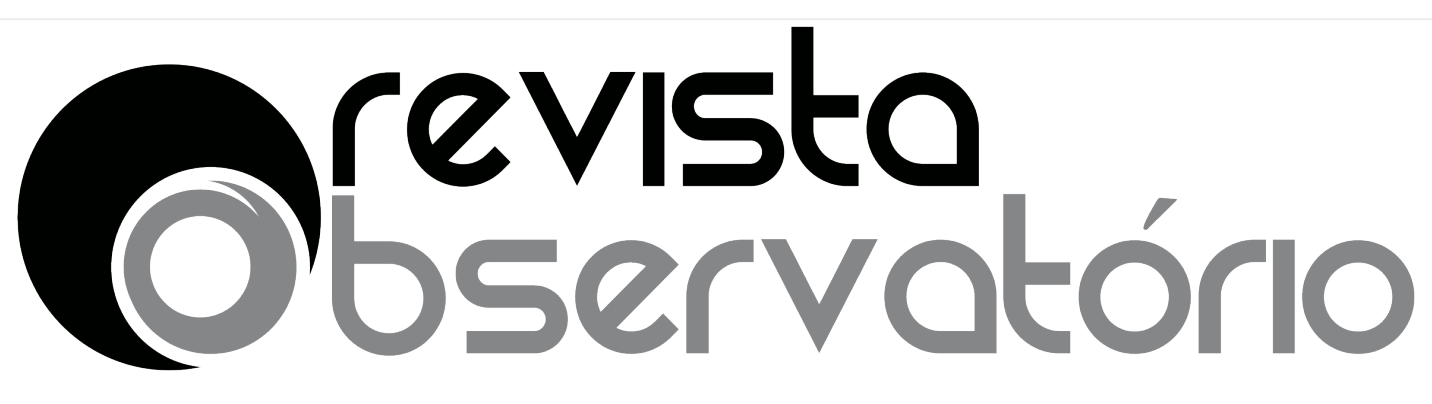

ISSN n² 2447-4266

Vol. 4, n. 2, Abril-Junho. 2018

DOI: http://dx.doi.org/10.20873/uft.2447-4266.2018v4n2p28

No artigo POR QUE E COMO FAZER HISTÓRIA DA REFORMA PROTESTANTE NO BRASIL, Francisca Jaquelini de Souza Viração faz uma discussão da importância da Reforma Protestante para a formação de um historiador. Com uma proposta de por que e como fazer uma História da Reforma no Brasil, apontando caminhos que passam por um dos maiores historiadores do protestantismo no Brasil que foi Emile G. Leonárd e um dos maiores intérpretes da Reforma nos dias atuais que é Alister Mcgrath.

Em COMO É POSSÍVEL AS UNIVERSIDADES ACOMPANHAREM AS INOVAÇÕES NO TELEJORNALISMO BRASILEIRO?, Paulo Eduardo Lins Cajazeira e Thiago Pedro Malkowski apresentam propostas de atividades que promovam o aprendizado do fazer telejornalismo visto o contexto atual das inovações tecnológicas e não tecnológicas realizadas no telejornalismo brasileiro. Parte-se do pressuposto que as inovações estão ocorrendo de forma cada vez mais acelerada e que as universidades necessitam ampliar as possibilidades de ensino para que os futuros jornalistas cheguem ao mercado de trabalho com amplo conhecimento prático e teórico, não só técnico, mas dos processos de produção de imagens que são alterados constantemente por consequência das inovações.

No artigo IMPRENSA E FAVELAS, REPRESENTAÇÕES E POLÍTICAS, Daniella Guedes Rocha analisa os diferentes enquadramentos sobre as favelas encontrados na imprensa carioca desde o fim do século $X X$, identificando uma relação entre estas representações e as políticas públicas voltadas para aqueles espaços em cada período. De antro de doenças, num momento em que a política higienista era dominante, ao espaço da criminalidade, quando a favela se torna essencialmente um problema de segurança pública, as representações e as políticas caminham juntas no tempo.

Em QUANTO VALE UM LIKE?: A publicidade de alimentos e a organização comunicada no Amazonas, Maria Emília Oliveira Pereira Abbud e Ayla Shamênia Viana do Nascimento Analisam a influência e avaliam as publicidades alimentícias regionais veiculadas no Facebook foram os propósitos para a produção do presente artigo. Com a 


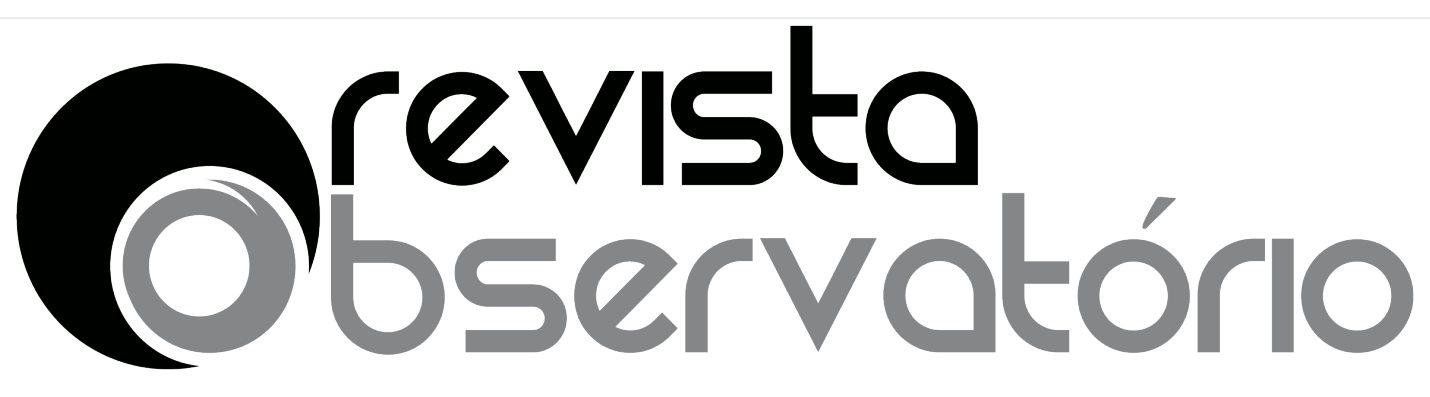

ISSN n² 2447-4266

Vol. 4, n. 2, Abril-Junho. 2018

DOI: http://dx.doi.org/10.20873/uft.2447-4266.2018v4n2p28

intenção de estabelecer uma relação entre as publicidades veiculadas no Facebook e a organização comunicada proposta por Baldissera (2009), apresenta-se uma pesquisa quanti e qualitativa realizada a partir das publicações de organizações regionais do ramo alimentício na cidade de Manaus.

Já no artigo ACESSO À INFORMAÇÃO COMO FERRAMENTA DE COMBATE À CORRUPÇÃO POR JORNALISTAS INVESTIGATIVOS, Veronica Rufino Sousa e Pedro Benevides analisam a aquisição de informações públicas por jornalistas investigativos no combate à corrupção, tomando como exemplo a série de reportagens do Programa Fantástico da Rede Globo, "Cadê o dinheiro que tava aqui".

\section{Em O SIQUEIRISMO NO CONTEXTO DAS FORMAS POLÍTICAS DE DOMINAÇÃO NO}

BRASIL, Sandoval Antunes de Souza faz uma análise do siqueirismo comparativamente a outras formas de dominação, na perspectiva weberiana, no Brasil contemporâneo. $O$ interesse foi pontuar, em um recorte deliberado de algumas formas de poder que possam servir à percepção do que é o siqueirismo no Tocantins e compará-lo com outros personagens da política brasileira na segunda metade do século $X X$.

No artigo CRIAÇÃO MUSICAL \& TEORIAS DA COMUNICAÇÃO (um relato sobre o aprendizado crítico e lúdico através da música), Adriana Schryver Kurtz resgata a experiência com a utilização da Aprendizagem Baseada em Projeto (ABP) para a Disciplina de Teorias da Comunicação da Escola Superior de Propaganda e Marketing (ESPM-Sul), que resultou na criação por parte dos estudantes de músicas originais, versões ou paródias críticas acerca das teorias, numa combinação de resgate conceitual e teórico e esforço autoral.

Em REGIMES DE INTERAÇÃO EM UMA NARRATIVA DA REPERCUSSÃO: O Boticário, os "Casais", Malafaia e "eu", José Maria Mendes Pereira Junior e Rogério Covaleski discutem as narrativas da repercussão materializados neste artigo pela publicidade de $\mathrm{O}$ Boticário para o Dia dos Namorados (2015) e a repercussão posterior a sua veiculação, que permite refletir 


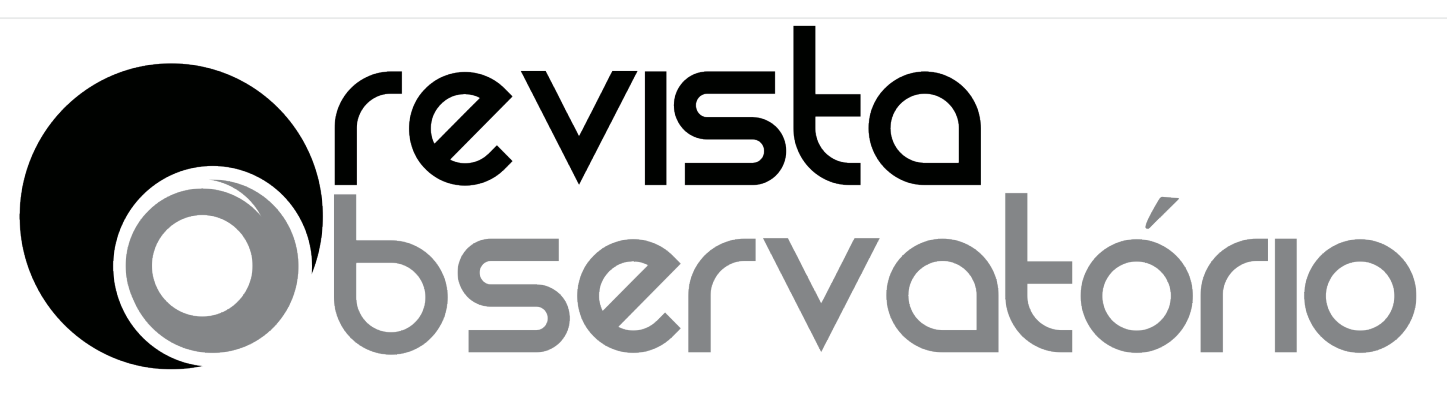

ISSN n² 2447-4266

Vol. 4, n. 2, Abril-Junho. 2018

DOI: http://dx.doi.org/10.20873/uft.2447-4266.2018v4n2p28

sobre a dinâmica relação entre as marcas e seus consumidores no contexto de cultura participativa (JENKINS, 2008), em que os atos funcionais da publicidade (adesão e compra) misturam-se com as apropriações que o "receptor" faz das mensagens publicitárias, usando-as como mais um elemento constituinte de seu tecido social.

Já no artigo NEGOCIAÇÃO COM ATINGIDOS NA IMPLANTAÇÃO DE USINAS HIDRELÉTRICAS: A experiência dos atores e o tempo fazem a diferença, Adila Maria Taveira de Lima e Elineide Eugênio Marques discorrem sobre como ocorreram os processos de construção de grandes projetos de desenvolvimento, analisando como estudo de caso, a implementação de três usinas hidrelétricas no Rio Tocantins, focando na experiência das partes envolvidas, e se esta é usada como diferencial na fase de negociação com os atingidos. As informações foram originadas por meio de análise documental e entrevistas semiestruturadas com os atores envueltos.

Em INTEGRAÇÃO DA MORALIDADE AO SELF: perspectivas atuais da psicologia e contribuições para a educação moral, Viviane Potenza Guimarães Pinheiro elucida conceitos centrais da psicologia que contribuem com a ideia da moralidade integrada ao self, de forma a clarificar os desafios que têm sido enfrentados por teóricos que partem de uma visão menos fragmentada do ser humano. Portanto, explicita as bases teóricas do conceito de identidade moral e os desdobramentos deste para a compreensão acerca da elaboração de valores, apresentando como as demandas atuais desse campo de estudos impactam a educação moral e lhes indicam novas frentes de trabalho.

No artigo A POÉTICA VISUAL DE ISAIAS MILIANO: Arte e Arqueologia na Amazônia, Leila Adriana Baptaglin e Acsa da Silva Ribeiro entender o processo de criação e poética do artista roraimense Isaias Miliano, por meio da obra do artista intitulada Sol, onde verificamos que em seu trabalho há o estudo sobre a identidade de Roraima.

Em A EDUCAÇÃO PARA A COMPETITIVIDADE: o retrato da proposta pedagógica na comunicação das escolas privadas de Santa Maria/RS, Janderle Rabaiolli e Paula Xavier 


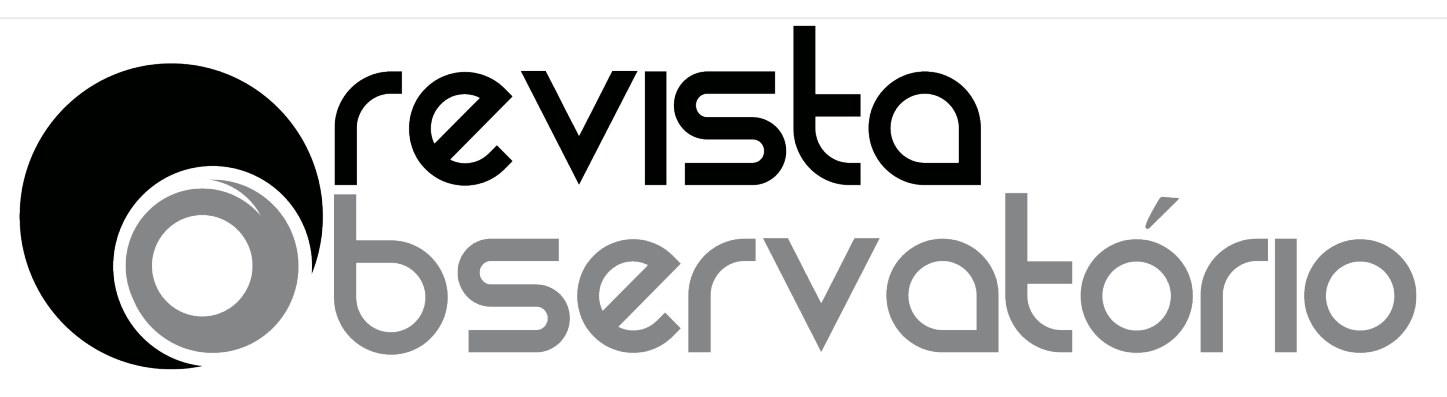

ISSN n² 2447-4266

Vol. 4, n. 2, Abril-Junho. 2018

DOI: http://dx.doi.org/10.20873/uft.2447-4266.2018v4n2p28

Corrêa discutem a relação entre a proposta pedagógica e a comunicação das escolas privadas de Santa Maria/RS, apontando evidências de competitividade. A pesquisa recorre a entrevistas com responsáveis por escolas privadas da cidade e análise de materiais de comunicação. A partir da aproximação com a perspectiva da análise discursiva de Fiorin (2014), busca-se identificar os dispositivos semânticos, presentes no discurso das entrevistas e da comunicação das escolas, que se referem à competitividade.

Na seção ENSAIOS, o artigo LE MILITANT POLITIQUE A L'EPREUVE DU DIFFEREND, de Viviane Horta Generoso apresenta um exemplo do conceito de différend, original e pragmático: o caso de Jean-François Lyotard. Para a autora, a ocorrência de um evento inesperado causará uma fissura no centro deste engajamento existencial. Essa mudança acontecerá devido a um sentimento de suspeita sobre a legitimação do discurso marxista. Esse sentimento abre uma ferida no militante, à medida em que ele começa a suspeitar da "validade do discurso marxista em compreender as mudanças do mundo contemporâneo". Esse sentimento assinala que existe "alguma coisa" que ele nomeará a posteriori différend,.

Já o artigo A DESORIENTAÇÃO GERAL, de Plínio W. Prado Jr. se interroga sobre a situação de impasse geral na qual vivemos no momento presente, devido à crise profunda da política ocidental moderna e, portanto, da condição histórica ela mesma, enquanto promessa de emancipação dos sujeitos. A falta geral de horizonte, o desaparecimento de um verdadeiro projeto crítico, histórico-político, o vazio de sentido que uma política reduzida à gestão do sistema liberal deixa na sua ruína, caracterizam esse impasse.

Na seção RESENHAS, temos a percepção de Keila Fernandes Santos sobre o livro Comunicar y educar en el mundo que viene, de Roberto Aparici e David Garcia Marin sobre o debate entre a escola, as mídias comunicacionais e o mundo atual, bem como de outros pesquisadores que discutem a temática. 


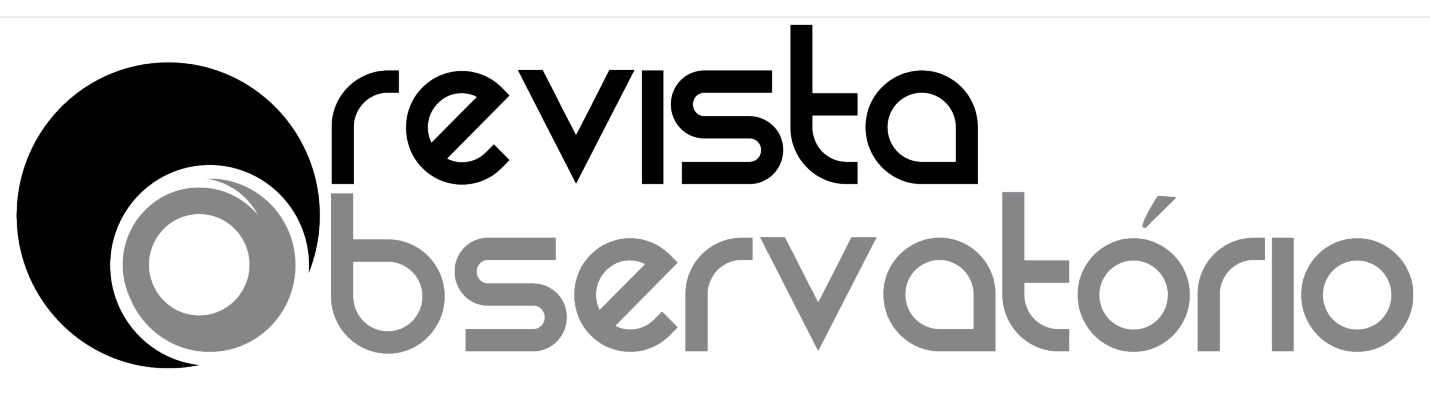

ISSN n² 2447-4266

Vol. 4, n. 2, Abril-Junho. 2018

DOI: http://dx.doi.org/10.20873/uft.2447-4266.2018v4n2p28

Na seção ENTREVISTAS, temos a entrevista realizada pelo professor Geraldo da Silva Gomes com o professor Piki Ish-Shalom intitulada THE CULTURE OF VIOLENCE AND UNSTABLE PROCESSES FOR THE MAINTENANCE OF PEACE, que esteve na UFT em 2017 partilhando seus estudos sobre política e oriente médio.

$\mathrm{E}$, na seção VISUALIDADES, temos a produção NAS TRANSPARÊNCIAS DA CIDADE PRÁTICA IMAGÉTICA, PERFORMATIVA E RITUAL, de Ricardo Malveira, Renata Ferreira da Silva, Renata Patrícia da Silva e Amanda Maurício Pereira Leite buscam promover uma breve discussão sobre prática artística como estratégia para perceber o espaço urbano da cidade de Palmas como lugar de intervenção e pesquisa. A percepção de transparências são os resultados da performance-instalação intitulada "Na rotatória tem encruzilhada", organizada pelo grupo de pesquisa Transver.

E, finalizando a seção, a produção (FOTO) IMAGINO (GRAFIAS): a poética do ficcionar, de Maria dos Remédios de Brito e Manoel Januário da Silva Neto que trazem o ensaio visual fotográfico como um bloco de sensações que carrega uma potência poética dos sentidos. A imagem fotográfica liberta o que assim foi, pois diante da morte salta efetivamente a vida e, assim, é possível arriscar ficcionalidades quando a imagem não é.

Temos certeza de que você terá muito prazer na leitura, visualização e reflexão do novo número da Revista Observatório!

Palmas-TO, Abril de 2018.

Editores convidados/ Guest Editors/ Editores invitados

Prof. Dr. Geraldo da Silva Gomes, Universidade Estadual do Tocantins, Centro de Estudos e Aperfeiçoamento Funcional (Cesaf/MPTO)

Prof. Dr. Adriano Machado Oliveira, Universidade Federal do Tocantins (UFT), Brasil. Profa. Dra. Juciley Silva Evangelista Freire, Universidade Federal do Tocantins (UFT), Brasil. 


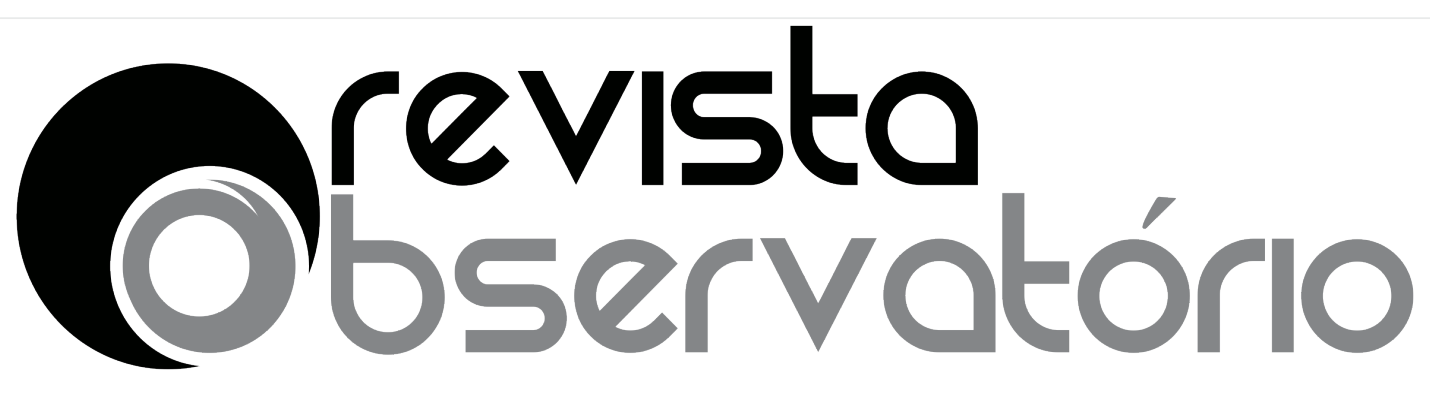

ISSN n² 2447-4266

Vol. 4, n. 2, Abril-Junho. 2018

DOI: http://dx.doi.org/10.20873/uft.2447-4266.2018v4n2p28

Editor Geral / Chief Editor / Editor general

Prof. Dr. Francisco Gilson Rebouças Porto Junior, Universidade Federal do Tocantins (UFT),

Brasil.

\section{Referências}

ABBUD, M. E. O. P.; NASCIMENTO, A. S. QUANTO VALE UM LIKE?: A publicidade de alimentos e a organização comunicada no Amazonas. Revista Observatório, v. 4, n. 2, p. 733755, 1 abr. 2018.

ARAÚJO, M. Z. F. DE; SANTOS, J. S.; DIFABIO, E. H. CAMINOS SOSTENIBLES PARA LA ENSEÑANZA DE LA LENGUA MATERNA EN LAS SERIES INICIALES. Revista Observatório, v. 4, n. 2, p. 516-538, 1 abr. 2018.

BAPTAGLIN, L. A.; RIBEIRO, A. DA S. A POÉTICA VISUAL DE ISAIAS MILIANO: Arte e Arqueologia na Amazônia. Revista Observatório, v. 4, n. 2, p. 931-949, 1 abr. 2018.

BATISTA, A. S.; MACIEL, W. C. PRISÃO COMO GUETO: a dinâmica de controle e de extermínio de jovens negros pobres. Revista Observatório, v. 4, n. 2, p. 174-200, 1 abr. 2018.

BERENGUER, B. Z. COMUNICACIÓN, PERIODISMO Y VIOLENCIAS CONTRA LAS MUJERES EN ESPAÑA. Reflexiones en torno a un estado de la cuestión. Revista Observatório, v. 4, n. 2, p. 80-117, 1 abr. 2018.

BIANCHI, G. S.; BRITO, N. R. DE. RÁDIOS COMUNITÁRIAS NO SUL DO MARANHÃO CONTEXTOS E LIMITAÇÕES DO TRABALHO RADIOJORNALÍSTICO. Revista Observatório, v. 4, n. 2, p. 596-623, 1 abr. 2018.

BITTENCOURT, R. N. A AGONIA DO ESPÍRITO EMANCIPADOR DA EDUCAÇÃO PERANTE A INTEGRAÇÃO ESPETACULAR DA SOCIEDADE DE CONSUMO NA FORMAÇÃO ALIENADA. Revista Observatório, v. 4, n. 2, p. 414-432, 1 abr. 2018.

BRITO, M. DOS R. DE; SILVA NETO, M. J. DA. (FOTO) IMAGINO (GRAFIAS): a poética do ficcionar. Revista Observatório, v. 4, n. 2, p. 1046-1056, 1 abr. 2018.

BUENO, W. DA C. GESTÃO DA COMUNICAÇÃO EM DESASTRES AMBIENTAIS: conflitos de interesse, de práticas e de discursos. Revista Observatório, v. 4, n. 2, p. 539-569, 1 abr. 2018.

CARVALHO, G. O. M. DE; PEREIRA, O. DE C. M.; SANTOS, M. A. DOS. PALMAS EM TRÊS ATOS: projeto urbanístico, implantação e consolidação da capital do Tocantins. Revista Observatório, v. 4, n. 2, p. 236-264, 1 abr. 2018.

CÔRTE, B.; SANTOS, B. S. M. D. EM NOME DO CUIDADO SE NATURALIZA A VIOLÊNCIA: O caso da contenção. Revista Observatório, v. 4, n. 2, p. 279-297, 1 abr. 2018. 


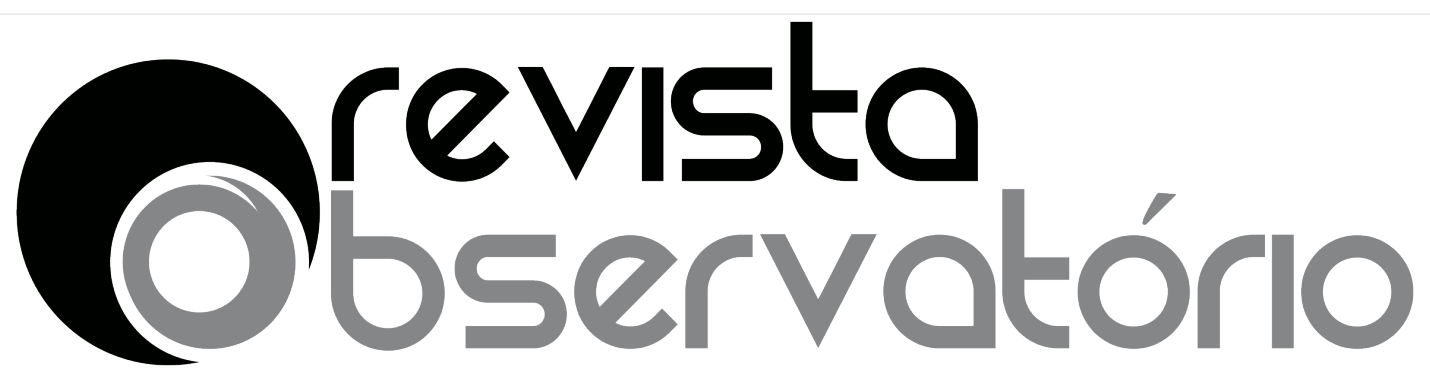

ISSN n² 2447-4266

Vol. 4, n. 2, Abril-Junho. 2018

DOI: http://dx.doi.org/10.20873/uft.2447-4266.2018v4n2p28

DEBORD, Guy "Perspectives de Modification Consciente de la vie Quotidiene". Internacionale Situationniste, n 6, Agosto de 1961.

DEBORD, Guy Panegírico. Lisboa: Antígona, 1995.

DEBORD, Guy. A Sociedade do Espetáculo. Rio de Janeiro: Contraponto, 1997a.

DEBORD, Guy. Considerações sobre a Sociedade do Espetáculo. In: A Sociedade do Espetáculo. Rio de Janeiro: Contraponto, 1997b.

FREIRE, J. C. DA S. AUTONOMIA DOCENTE NA CONTEMPORANEIDADE: fundamentos, condições e possibilidades. Revista Observatório, v. 4, n. 2, p. 321-345, 1 abr. 2018.

FREIRE, J. S. E. A CONSTITUIÇÃO DO SER SOCIAL: TRABALHO E FORMAÇÃO HUMANA EM MARX. Revista Observatório, v. 4, n. 2, p. 391-413, 1 abr. 2018.

FROMM, Erich. Psicanálise da Sociedade Contemporânea. $8^{a}$ Ed. Rio de Janeiro, Zahar, 1976. FROMM, Erich. Ter ou Ser? 10a Ed., Rio de Janeiro: Zahar, 1988.

GENEROSO, V. H. LE MILITANT POLITIQUE A L'EPREUVE DU DIFFEREND. Revista Observatório, v. 4, n. 2, p. 973-994, 1 abr. 2018.

GOMES, G. DA S. ELEMENTOS PARA ENTENDIMENTO DOS PROCESSOS COMUNICACIONAIS: Os espaços dos Regimes Prisionais Semiaberto e Fechado em Palmas-TO. Revista Observatório, v. 4, n. 2, p. 201-235, 1 abr. 2018.

ISH-SHALOM, P. THE CULTURE OF VIOLENCE AND UNSTABLE PROCESSES FOR THE MAINTENANCE OF PEACE. Revista Observatório, v. 4, n. 2, p. 1026-1032, 1 abr. 2018.

KONZEN, J. O. A RECONCILIAÇÃO FORMAL ENTRE TEORIA E PRÁTICA: UMA PROBLEMATIZAÇÃO DA CONCEPÇÃO PRAGMÁTICA. Revista Observatório, v. 4, n. 2, p. 346390, 1 abr. 2018.

KURTZ, A. S. CRIAÇÃO MUSICAL \& TEORIAS DA COMUNICAÇÃO (um relato sobre o aprendizado crítico e lúdico através da música. Revista Observatório, v. 4, n. 2, p. 820-846, 1 abr. 2018.

LIMA, A. M. T. DE; MARQUES, E. E. NEGOCIAÇÃO COM ATINGIDOS NA IMPLANTAÇÃO DE USINAS HIDRELÉTRICAS: A experiência dos atores e o tempo fazem a diferença. Revista Observatório, v. 4, n. 2, p. 870-899, 1 abr. 2018.

LINS CAJAZEIRA, P. E.; MALKOWSKI, T. P. COMO É POSSÍVEL AS UNIVERSIDADES ACOMPANHAREM AS INOVAÇÕES NO TELEJORNALISMO BRASILEIRO?. Revista Observatório, v. 4, n. 2, p. 692-711, 1 abr. 2018.

MALVEIRA, R.; SILVA, R. F. DA; SILVA, R. P. DA; LEITE, A. M. P. NAS TRANSPARÊNCIAS DA CIDADE PRÁTICA IMAGÉTICA, PERFORMATIVA E RITUAL. Revista Observatório, v. 4, n. 2, p. 1033-1045, 1 abr. 2018.

MANSO, M. E. G.; MELLO, R. G. R. DE; LOPES, R. G. DA C. MÍDIAS DIGITAIS E AS INVISÍVEIS VIOLÊNCIAS CONTRA IDOSOS. Revista Observatório, v. 4, n. 2, p. 265-278, 1 abr. 2018.

MENDONÇA, M. C. "APRENDER A LER 'PRA' ENSINAR MEUS CAMARADAS": Reflexões sobre literacia e educação na pós-modernidade. Revista Observatório, v. 4, n. 2, p. 570-595, 1 abr. 2018. 


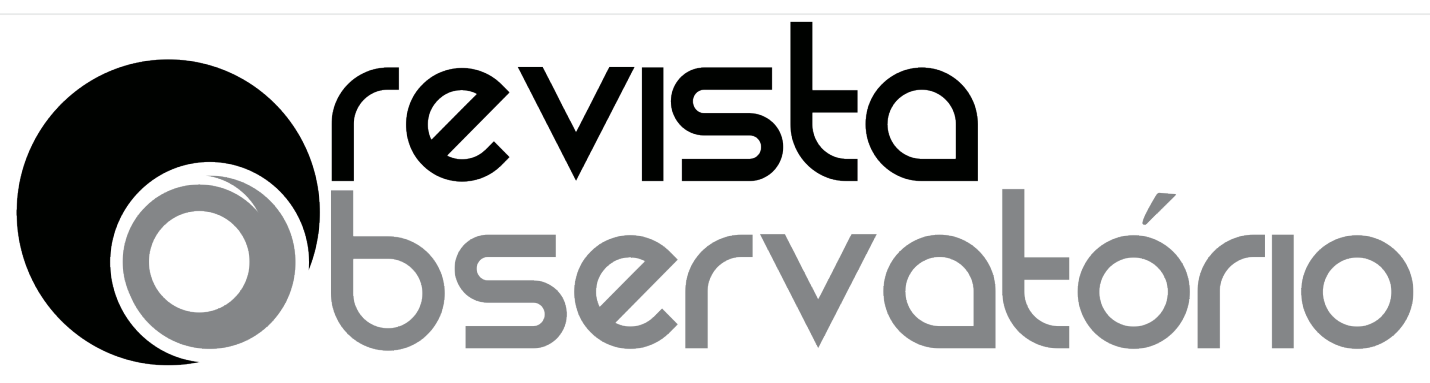

ISSN n² 2447-4266

Vol. 4, n. 2, Abril-Junho. 2018

DOI: http://dx.doi.org/10.20873/uft.2447-4266.2018v4n2p28

MESSEDER, S. A.; NASCIMENTO, C. G. DO. CINE BLASFÊMIA: uma narrativa de censura, enfrentamentos e (re)existências. Revista Observatório, v. 4, n. 2, p. 118-143, 1 abr. 2018.

OLIVEIRA, A. M.; MACHADO, M. ADOLESCÊNCIA, CULTURA E SOCIEDADE DO ESPETÁCULO. Revista Observatório, v. 4, n. 2, p. 458-479, 1 abr. 2018.

PEREIRA JUNIOR, J. M. M.; COVALESKI, R. REGIMES DE INTERAÇÃO EM UMA NARRATIVA DA REPERCUSSÃO: O Boticário, os "Casais", Malafaia e "eu". Revista Observatório, v. 4, n. 2, p. 847-869, 1 abr. 2018.

PEREIRA, T. K. QUE AUSCHWITZ NÃO SE REPITA: a educação contra a frieza na primeira infância. Revista Observatório, v. 4, n. 2, p. 500-515, 1 abr. 2018.

PINHEIRO, V. P. G. INTEGRAÇÃO DA MORALIDADE AO SELF: perspectivas atuais da psicologia e contribuições para a educação moral. Revista Observatório, v. 4, n. 2, p. 900930, 1 abr. 2018.

PINHO, M. J. DE; PASSOS, V. M. DE A. COMPLEXIDADE, ECOFORMAÇÃO E TRANDISCIPLINARIDADE: por uma formação docente sem fronteiras teóricas. Revista Observatório, v. 4, n. 2, p. 433-457, 1 abr. 2018.

PONTES, F. S.; KOSTER, G. R. DO CONTEÚDO À NARRATIVA: um estudo da Pública - Agência de Reportagem e Jornalismo Investigativo. Revista Observatório, v. 4, n. 2, p. 651-675, 1 abr. 2018.

PRADO JR., P. W. A DESORIENTAÇÃO GERAL. Revista Observatório, v. 4, n. 2, p. 995-1014, 1 abr. 2018.

RABAIOLLI, J.; CORRÊA, P. X. A EDUCAÇÃO PARA A COMPETITIVIDADE: o retrato da proposta pedagógica na comunicação das escolas privadas de Santa Maria/RS. Revista Observatório, v. 4, n. 2, p. 950-972, 1 abr. 2018.

ROCHA, D. G. IMPRENSA E FAVELAS, REPRESENTAÇÕES E POLÍTICAS. Revista Observatório, v. 4, n. 2, p. 712-732, 1 abr. 2018.

SANTOS, K. F. COMUNICAR Y EDUCAR EN EL MUNDO QUE VIENE. Revista Observatório, v. 4, n. 2, p. 1015-1025, 1 abr. 2018.

SANTOS, V. M.; ALBERGARIA, V. P. ENTRE SUJEITO E PERSONAGEM: a morte de Roberto Bolaños e a vida de Chespirito. Revista Observatório, v. 4, n. 2, p. 624-650, 1 abr. 2018.

SARAIVA, R. A REGULAÇÃO DA VIOLÊNCIA MEDIÁTICA EM PORTUGAL. Revista Observatório, v. 4, n. 2, p. 144-173, 1 abr. 2018.

SEGNI, S. D. RELEYENDO ADOLESCENCIA, POSMODERNIDAD Y ESCUELA: Veinte años después. Revista Observatório, v. 4, n. 2, p. 480-499, 1 abr. 2018.

SOUSA, V. R.; BENEVIDES, P. ACESSO À INFORMAÇÃO COMO FERRAMENTA DE COMBATE À CORRUPÇÃO POR JORNALISTAS INVESTIGATIVOS. Revista Observatório, v. 4, n. 2, p. 756782, 1 abr. 2018.

SOUZA, S. A. DE. O SIQUEIRISMO NO CONTEXTO DAS FORMAS POLÍTICAS DE DOMINAÇÃO NO BRASIL. Revista Observatório, v. 4, n. 2, p. 783-819, 1 abr. 2018. 


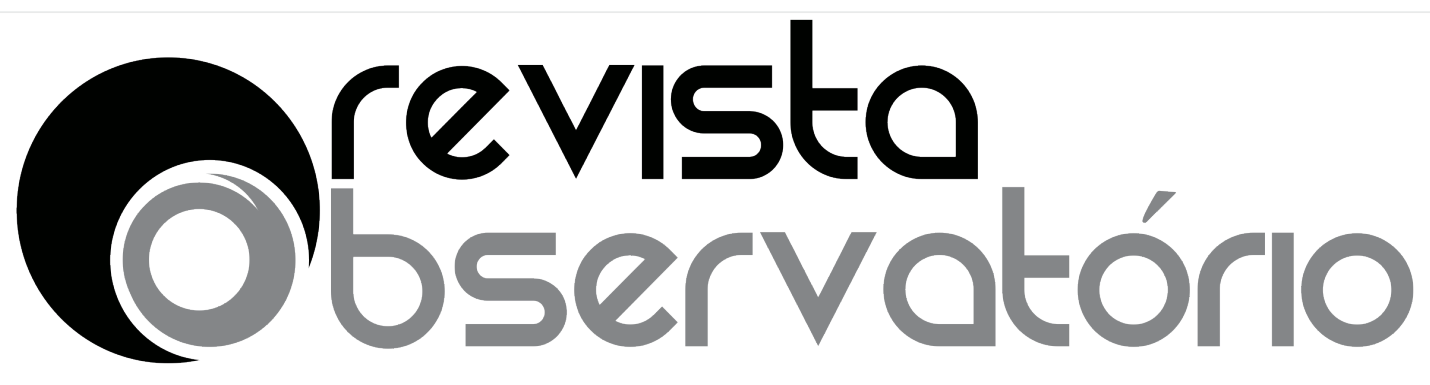

ISSN n² 2447-4266

Vol. 4, n. 2, Abril-Junho. 2018

DOI: http://dx.doi.org/10.20873/uft.2447-4266.2018v4n2p28

TARÍN SANZ, A.; CARMENATI GONZÁLEZ, M. SOLO LOS HOMBRES SON POLICÍAS: orden público, violencias heteronormadas y sus reflejos en The Wire. Revista Observatório, v. 4, n. 2, p. 49-79, 1 abr. 2018.

TERNES, J. MODERNIDADE, CIÊNCIA, FILOSOFIA. Revista Observatório, v. 4, n. 2, p. 298-320, 1 abr. 2018.

VIRAÇÃO, F. J. D. S. POR QUE E COMO FAZER HISTÓRIA DA REFORMA PROTESTANTE NO BRASIL. Revista Observatório, v. 4, n. 2, p. 676-691, 1 abr. 2018. 